This item was submitted to Loughborough's Research Repository by the author.

Items in Figshare are protected by copyright, with all rights reserved, unless otherwise indicated.

\title{
Influence of dietary nitrate supplementation on local sweating and cutaneous vascular responses during exercise in a hot environment
}

\section{PLEASE CITE THE PUBLISHED VERSION}

https://doi.org/10.1007/s00421-018-3889-9

\section{PUBLISHER}

(C) Springer

\section{VERSION}

AM (Accepted Manuscript)

\section{PUBLISHER STATEMENT}

This work is made available according to the conditions of the Creative Commons Attribution-NonCommercialNoDerivatives 4.0 International (CC BY-NC-ND 4.0) licence. Full details of this licence are available at: https://creativecommons.org/licenses/by-nc-nd/4.0/

\section{LICENCE}

CC BY-NC-ND 4.0

\section{REPOSITORY RECORD}

Amano, Tatsuro, Dai Okushima, Brynmor C. Breese, Stephen J. Bailey, Shunsaku Koga, and N. Kondo. 2019. "Influence of Dietary Nitrate Supplementation on Local Sweating and Cutaneous Vascular Responses During Exercise in a Hot Environment". figshare. https://hdl.handle.net/2134/33213. 


\section{Influence of dietary nitrate supplementation on local sweating and cutaneous vascular responses during exercise in a hot environment}

Tatsuro Amano ${ }^{1,2}$, Dai Okushima ${ }^{3}$, Brynmor C. Breese ${ }^{4}$, Stephen J. Bailey ${ }^{5}$, Shunsaku Koga ${ }^{3}$, and Narihiko Kondo ${ }^{1}$

${ }^{1}$ Laboratory for Applied Human Physiology, Graduate School of Human Development and Environment, Kobe University, Kobe, Japan

${ }^{2}$ Laboratory for Exercise and Environmental Physiology, Faculty of Education, Niigata University, Niigata, Japan

${ }^{3}$ Applied Physiology Laboratory, Kobe Design University, Kobe, Japan

${ }^{4}$ School of Biomedical \& Healthcare Sciences, Plymouth University, Plymouth, United Kingdom

${ }^{5}$ School of Sport, Exercise and Health Sciences, Loughborough University, United Kingdom

Running head: Beetroot juice and heat loss responses during exercise

Address for correspondence:

Narihiko KONDO, PhD,

Laboratory for Applied Human Physiology,

Graduate School of Human Development and Environment, Kobe University

3-11 Tsurukabuto, Nada-ku, Kobe 657-8501, Japan

Tel: +81-78-803-7816, Fax: +81-78-803-7929

E-mail: kondo@kobe-u.ac.jp 


\section{ABSTRACT}

2

3 Purpose: We investigated the influence of inorganic nitrate $\left(\mathrm{NO}_{3}{ }^{-}\right)$supplementation on local sweating and cutaneous vascular responses during exercise in hot conditions. Method: Eight healthy, young subjects were assigned in a randomized, double-blind, crossover design to receive $\mathrm{NO}_{3}{ }^{-}$-rich beetroot (BR) juice $\left(140 \mathrm{~mL} /\right.$ day, containing $\sim 8 \mathrm{mmol}$ of $\mathrm{NO}_{3}{ }^{-}$) and $\mathrm{NO}_{3}{ }^{-}$-depleted placebo (PL) juice (140 mL/day, containing $\sim 0.003 \mathrm{mmol}$ of $\mathrm{NO}_{3}{ }^{-}$) for 3 days.

8 On day 3 of supplementation, subjects cycled at an intensity corresponding to $55 \%$ of $\hat{V} \mathrm{O}_{2 \max }$

9 for 30 minutes in hot conditions $\left(30^{\circ} \mathrm{C}, 50 \%\right.$ relative humidity). Chest and forearm sweat rate (SR) and skin blood flow (SkBF), were measured continuously. Cutaneous vascular conductance (CVC) was calculated by SkBF/mean arterial pressure (MAP). Results: Prior to exercise, plasma $\mathrm{NO}_{3}{ }^{-}(21 \pm 6$ and $581 \pm 161 \mu \mathrm{M})$ and nitrite $\left(\mathrm{NO}_{2}{ }^{-}, 87 \pm 28\right.$ and $\left.336 \pm 156 \mathrm{nM}\right)$ concentrations were higher after BR compared to PL supplementation $(P \leq 0.011, n=6)$. Oesophageal, mean skin, and mean body temperatures during exercise were not different between conditions. In addition, BR supplementation did not affect SR, SkBF, and CVC during exercise. A lower MAP was found after 30 minutes of exercise following BR supplementation (112 \pm 6 and $103 \pm 6 \mathrm{mmHg}$ for PL and BR, respectively, $P=0.021$ ). Conclusion: These results suggest that inorganic $\mathrm{NO}_{3}{ }^{-}$supplementation, which increases the potential for $\mathrm{O}_{2}$-independent $\mathrm{NO}$ production, does not affect local sweating and cutaneous vascular responses, but attenuates blood pressure in young healthy subjects exercising in a hot environment.

KEYWORDS: Nitric oxide synthesis, thermoregulation, heat loss response, sweat glands

ABBREVIATIONS: ANOVA, analysis of variance; d, Cohen's d; CVC, cutaneous vascular conductance; HR, heart rate; $\dot{V} \mathrm{O}_{2 \max }$, maximal oxygen uptake; MAP, mean arterial blood pressure; $\mathrm{T}_{\mathrm{b}}$, mean body temperature; $\mathrm{T}_{\mathrm{sk}}$, mean skin temperature; $\mathrm{NO}_{3}{ }^{-}$, nitrate; $\mathrm{NO}$, nitric oxide; NOS, nitric oxide synthase; $\mathrm{NO}_{2}{ }^{-}$, nitrite; $\mathrm{T}_{\mathrm{es}}$, oesophageal temperature; $\eta_{\mathrm{p}}{ }^{2}$, partial eta-squared; RPE, rating of perceived exertion; $T_{\text {re }}$, rectal temperature; $S k B F$, skin blood flow; SD, standard deviation; SR, sweat rate 


\section{INTRODUCTION}

Sweating and cutaneous vasodilation are vital physiological functions that dissipate heat from the body during exercise. Previous studies suggest that nitric oxide (NO) is an important signalling molecule for modulating sweat rate (SR) and cutaneous blood flow in humans (Stapleton et al. 2014; Welch et al. 2009; Kellogg et al. 1998; McNamara et al. 2014; Wilkins et al. 2003; Fujii et al. 2016). There are two pathways for NO generation in humans. The most recognized is the enzymatic NO synthase (NOS) pathway, which catalyses the oxidation of

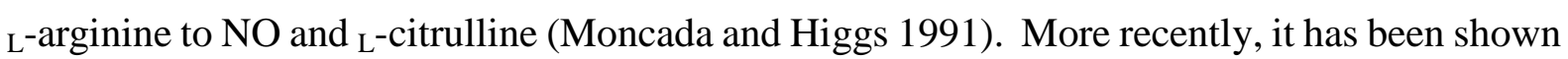
that $\mathrm{NO}$ can be produced $\mathrm{O}_{2}$-independently through the stepwise reduction of inorganic nitrate $\left(\mathrm{NO}_{3}{ }^{-}\right)$to nitrite $\left(\mathrm{NO}_{2}{ }^{-}\right)$and subsequently $\mathrm{NO}$ (i.e. $\mathrm{NO}_{3}{ }^{-} \rightarrow \mathrm{NO}_{2}{ }^{-} \rightarrow \mathrm{NO}$ pathway) (Lundberg et al. 2008). The importance of NOS-derived NO on physiological responses that promote heat loss is already well defined, as evidenced by a lower SR and cutaneous vasodilation during exercise or passive heat stress following inhibition of skin NOS activity (Welch et al. 2009; Kellogg et al. 1998; Wilkins et al. 2003; Stapleton et al. 2014; Fujii et al. 2016; Amano et al. 2017a). On the other hand, the influence of the $\mathrm{NO}_{3}{ }^{-} \rightarrow \mathrm{NO}_{2}{ }^{-} \rightarrow \mathrm{NO}$ pathway on heat loss responses during exercise has not been fully investigated.

Following ingestion, $\mathrm{NO}_{3}{ }^{-}$is absorbed and concentrated by the salivary glands for delivery to the oral cavity for second pass metabolism (Spiegelhalder et al. 1976). Here, oral microflora catalyses the reduction of $\mathrm{NO}_{3}{ }^{-}$to $\mathrm{NO}_{2}^{-}$(Duncan et al. 1995). Ingested $\mathrm{NO}_{2}{ }^{-}$is subsequently reduced to NO and other reactive nitrogen species in the acidic $\mathrm{pH}$ of the stomach (Benjamin et al. 1994). It is also clear that a portion of the ingested $\mathrm{NO}_{2}^{-}$passes into the systemic circulation, as evidenced by a dose-dependent increase in venous plasma $\left[\mathrm{NO}_{2}{ }^{-}\right]$after oral $\mathrm{NO}_{3}{ }^{-}$ingestion (Kapil et al. 2010; Wylie et al. 2013a). As this circulating $\mathrm{NO}_{2}{ }^{-}$arrives at the skin microvasculature, the ensuing fall in $\mathrm{Po}_{2}$ (Kerger et al. 1995) would be conducive to the reduction of $\mathrm{NO}_{2}{ }^{-}$to $\mathrm{NO}$ (Castello et al. 2006) and might promote increases in NO-mediated cutaneous vasodilation (Kellogg et al. 1998; Fujii et al. 2016; Wilkins et al. 2003; Shastry et al. 1998; McNamara et al. 2014). It is also possible for circulating $\mathrm{NO}_{2}{ }^{-}$to pass into the eccrine sweat glands (Weller et al. 1996). Subsequently, $\mathrm{NO}_{2}{ }^{-}$might be reduced to NO, a reaction that would be facilitated by the acidic pH present in eccrine sweat (Morimoto and Johnson 1967). In addition, $\mathrm{NO}_{3}{ }^{-}$secreted in sweat might undergo reduction to $\mathrm{NO}_{2}{ }^{-}$when exposed to dermal $\mathrm{NO}_{3}{ }^{-}$reductases with this $\mathrm{NO}_{2}^{-}$undergoing subsequent reduction to $\mathrm{NO}$ within the acidic 
65

66

67

68

69

70

conditions of the skin (Burry et al. 2001; Weller et al. 1996). This dermal NO then has the potential to diffuse through the skin to promote vasodilation (Vercelino et al. 2013). Therefore, $\mathrm{NO}_{3}{ }^{-}$supplementation has the potential to augment sweating and cutaneous vascular responses via NO-mediated signalling during exercise.

In contrast to the postulate that $\mathrm{NO}_{3}{ }^{-}$supplementation has the potential to augment $\mathrm{SR}$, it has recently been reported that dietary $\mathrm{NO}_{3}{ }^{-}$supplementation does not affect whole body sweat loss (indirectly inferred from changes in body mass) during submaximal treadmill walking in hot conditions (Kuennen et al. 2015). However, it is important to note the large inter-regional differences in local SR and skin blood flow (SkBF) previously reported across human skin (Havenith et al. 2008; Smith and Havenith 2011; Taylor and Machado-Moreira 2013; Kuno 1956; Hertzman and Randall 1948). Since higher SkBF would deliver more $\mathrm{NO}_{2}{ }^{-}$to the sweat gland, $\mathrm{NO}_{3}{ }^{-}$supplementation might be particularly effective at augmenting local SR at skin sites where blood flow is high (e.g. torso) compared to skin sites where blood flow is low (e.g. extremes) (Hertzman and Randall 1948). It has been reported that $\mathrm{NO}_{3}{ }^{-}$supplementation can increase cutaneous vasodilation to local heating (Keen et al. 2014) and whole body passive heat stress (Levitt et al. 2015). However, since disparate mechanisms underlie cutaneous blood flow regulation at rest and during exercise (McNamara et al. 2014; Fujii et al. 2016) and since the influence of $\mathrm{NO}_{3}^{-}$supplementation on regional SkBF has not been investigated, further research is required to explore whether the greater cutaneous blood flow after $\mathrm{NO}_{3}{ }^{-}$ supplementation is also manifest during exercise, and whether these effects might be site-specific.

The purpose of the present study was to investigate the influence of $\mathrm{NO}_{3}{ }^{-}$-rich beetroot juice (BR) supplementation on local sweating and cutaneous vascular responses during exercise in a hot environment. We hypothesized that BR supplementation would augment local sweating and cutaneous vasodilation on the chest to a greater extent than on the forearm during exercise in a hot condition.

\section{MATERIALS AND METHODS}

\section{Ethical approval}

Each participant was informed of the purpose and procedures of the study prior to providing written informed consent. This study was approved by the Human Subjects Committee of the 
99 Graduate School of Human Development and Environment, Kobe University (Kobe, Japan), and conformed to the standards set forth in the latest revision of the Declaration of Helsinki.

\section{Participants}

103 Five males and three females participated in the present study (mean \pm SD age: $24 \pm 4$ years, height: $1.70 \pm 0.09 \mathrm{~m}$, and mass: $62.7 \pm 10.3 \mathrm{~kg}$, maximum oxygen uptake, $\dot{V}_{2} \mathrm{O}_{2 \max }: 43 \pm 6$ $\mathrm{ml} / \mathrm{kg} / \mathrm{min}$ ). Participants were healthy and active and were excluded if they had history of hypertension, heart disease, diabetes, autonomic disorders or smoking. All participants were not currently taking prescription medication. None of the females were using oral contraceptives and all participated in the experimental testing sessions either during the self-reported follicular or luteal phases without crossing phases. All experiments were conducted between the month of June and August.

\section{Dietary intervention}

113 Participants were randomly assigned in a crossover, double-blind design to receive 3 days of

114 dietary supplementation with $\mathrm{NO}_{3}{ }^{-}$-rich beetroot juice (BR) $\left(140 \mathrm{~mL} / \mathrm{day} ; \sim 8 \mathrm{mmol} \mathrm{NO}{ }_{3}^{-}\right.$; Beet

115 It, James White Drinks, Ipswich, UK) or $\mathrm{NO}_{3}{ }^{-}$-depleted BR as a placebo (PL; $140 \mathrm{~mL} /$ day;

$1160.0034 \mathrm{mmol} \mathrm{NO}_{3}{ }^{-}$; Beet It, James White Drinks, Ipswich, UK). The dose of BR administered 117 was based on a previous dose-response study reporting an increase in plasma $\mathrm{NO}_{3}{ }^{-}$and $\mathrm{NO}_{2}{ }^{-}$ 118 concentration and peak reduction in systolic blood pressure following the ingestion of $8 \mathrm{mmol}$ $119 \mathrm{NO}_{3}{ }^{-}$(Breese et al. 2017; Cermak et al. 2012; Lansley et al. 2011; Kuennen et al. 2015). The $120 \mathrm{NO}_{3}{ }^{-}$-depleted $\mathrm{BR}$ placebo beverage was identical in color, taste, smell and texture to the 121 experimental $\mathrm{NO}_{3}{ }^{-}$-rich $\mathrm{BR}$ beverage. The PL beverage was created by passage of the juice, 122 before pasteurization, through a column containing Purolite A520E ion exchange resin, which 123 selectively removes $\mathrm{NO}_{3}{ }^{-}$ions. Four participants began with the $\mathrm{BR}$ condition, and the other 124 four participants began with the PL condition. The subjects were instructed to consume the beverages (70 $\mathrm{mL}$ in the morning and afternoon) on days 1-2 of the supplementation period. On

126 day 3 , the subjects were instructed to consume the beverages over a 10-min period, $2 \mathrm{~h}$ prior to 127 the start of the exercise test (see below), based on recent evidence that plasma $\left[\mathrm{NO}_{2}{ }^{-}\right]$peaks at 128 approximately 2-2.5 h post-administration of BR containing $8.4 \mathrm{mmol} \mathrm{NO}_{3}{ }^{-}$(Wylie et al. 129 2013b). A 7-day washout period separated each supplementation period. Throughout the study, 130 participants were asked to refrain from consumption of green leafy vegetables (e.g. Spinach), 131 processed meats (e.g. Bacon), and Japanese traditional foods (e.g. Seaweed, Sayaingen beans, 
132 Chin gin cai) which are high in $\mathrm{NO}_{3}{ }^{-}$(Sobko et al. 2010). Since the oral bacteria are integrated

133 for reducing $\mathrm{NO}_{3}{ }^{-}$to $\mathrm{NO}_{2}{ }^{-}$in vivo (Govoni et al. 2008), participants were also asked to refrain

134 the use of mouthwash.

\section{Exercise protocol}

137 After arrival at the laboratory on experimental days, venous blood samples were drawn from an antecubital vein in a seated position in an air-conditioned room $\left(\sim 27^{\circ} \mathrm{C}\right)$ from 6 of 8 subjects who consented to venipuncture. All exercise trials were performed in an environmental chamber (SR-3000; Nagano Science, Osaka, Japan) maintained at an ambient temperature of $30^{\circ} \mathrm{C}$ and relative humidity of $50 \%$ with minimal air movement. Upon entering the chamber, participants rested in the semi-supine position for a minimum of 60 minutes while instruments were attached. After recording the baseline data for 5 minutes, participants started cycling at an exercise intensity of $55 \%$ of maximum oxygen uptake ( $\left(\mathrm{VO}_{2 \max }\right)$ for 30 minutes.

Measurements

147 Oesophageal temperature $\left(\mathrm{T}_{\mathrm{es}}\right)$ was measured continuously using a thermocouple temperature 148 probe (Inui Engineering, Higashi Osaka, Japan). The tip of the probe was covered by silicon 149 and inserted at a distance of one-fourth of the participant's standing height from the external nares past the nostril and into the esophagus. Skin temperatures were measured at six skin sites using the same thermocouples attached with surgical tape. Mean skin temperature $\left(\mathrm{T}_{\mathrm{sk}}\right)$ was calculated using 6 skin temperatures weighted to the regional proportions determined as follows: forehead $7 \%$, abdomen $35 \%$, forearm $14 \%$, hand $5 \%$, lower leg $13 \%$, and foot $7 \%$

154 (Mitchell and Wyndham 1969). The mean body temperature $\left(\mathrm{T}_{\mathrm{b}}\right)$ was calculated as $0.8 \times \mathrm{T}_{\mathrm{es}}+$ $0.2 \times \mathrm{T}_{\text {sk }}$ (Stolwijk and Hardy 1966).

Local SR was measured continuously on left ventral forearm (centre of the forearm) and chest (under the left clavicle) using a ventilated plastic capsule $\left(3.14 \mathrm{~cm}^{2}\right)$ that was attached to the skin using collodion. Anhydrous nitrogen gas was passed through each capsule over the skin surface at a rate of $0.7 \mathrm{~L} \cdot \mathrm{min}^{-1}$. Water content from the effluent air was measured using a capacitance hygrometer (HMP50; Vaisala, Helsinki, Finland). An index of local SkBF on the forearm and chest were measured continuously using laser-Doppler velocimetry (ALF21; Advance, Tokyo, Japan) located adjacent to the ventilated capsule. Cutaneous vascular 
165 (MAP). All temperature, SR and SkBF data were recorded at 1-s intervals using a data logger 166 (MX100; Yokogawa, Tokyo, Japan) and simultaneously displayed (MX100 standard software;

167 Yokogawa, Tokyo, Japan) and recorded. Heart rate (HR) and MAP were continuously 168 measured from left middle finger using the Finometer system (Finometer; Finapres Medical 169 Systems, Amsterdam, The Netherlands). Standardized calibration was conducted before each 170 trial. Ratings of perceived exertion (RPE) was measured every 5 minutes based on Borg 6-20 171 scale (Borg 1970).

172

173 Venous blood samples ( 4 ml) were drawn into lithium-heparin tubes $(7.5 \mathrm{ml}$ Monovette 174 Lithium Heparin, Sarstedt, Leicester, UK), which have very low levels of $\mathrm{NO}_{2}^{-}$and $\mathrm{NO}_{3}{ }^{-}$. 175 Within 3 min of collection, the samples were centrifuged at $2700 \mathrm{~g}$ and $4^{\circ} \mathrm{C}$ for $10 \mathrm{~min}$. Plasma 176 was extracted and immediately frozen at $-80^{\circ} \mathrm{C}$ for later analysis of $\mathrm{NO}_{2}{ }^{-}$and $\mathrm{NO}_{3}{ }^{-}$using a 177 modification of the chemiluminescence technique (Bateman et al. 2002). All glassware, 178 utensils, and surfaces were rinsed with deionized water to remove residual $\mathrm{NO}_{2}{ }^{-}$and $\mathrm{NO}_{3}{ }^{-}$prior 179 to analysis. Following defrosting at room temperature, the $\mathrm{NO}_{2}^{-}$of the undiluted 180 (non-deproteinized) plasma was determined by its reduction to NO in the presence of glacial 181 acetic acid and 4\% (w/v) aqueous NaI. The spectral emission of electronically excited nitrogen 182 dioxide, produced from the reaction of NO with ozone, was detected by a thermoelectrically 183 cooled, red-sensitive photomultiplier tube housed in a Sievers gas-phase chemiluminescence 184 nitric oxide analyzer (Sievers NOA 280i. Analytix Ltd, Durham, UK). The $\mathrm{NO}_{2}{ }^{-}$concentration 185 was determined by plotting signal $(\mathrm{mV})$ area against a calibration plot of $100 \mathrm{nM}$ to $1 \mu \mathrm{M}$ 186 sodium nitrite. Before determination of $\mathrm{NO}_{3}{ }^{-}$, samples were deproteinized using zinc sulfate $187\left(\mathrm{ZnSO}_{4}\right)$ /sodium hydroxide $(\mathrm{NaOH})$ precipitation. Aqueous $\mathrm{ZnSO}_{4}[300 \mu \mathrm{l} \%$ (w/v)] and 500 $188 \mu \mathrm{l} 0.18 \mathrm{M} \mathrm{NaOH}$ were added to $100 \mu \mathrm{l}$ of sample and vortexed for $30 \mathrm{~s}$ before being left to 189 stand at room temperature for $15 \mathrm{~min}$. Thereafter, samples were centrifuged at 4,000 rpm for 5 $190 \mathrm{~min}$, and the supernatant was removed for subsequent analysis. The $\mathrm{NO}_{3}{ }^{-}$concentration of the 191 deproteinized plasma sample was determined by its reduction to NO in the presence of $0.8 \%$ 192 (w/v) vanadium trichloride in $1 \mathrm{M} \mathrm{HCl}$. The production of $\mathrm{NO}$ was detected using the 193 chemiluminescence nitric oxide analyzer, as described above.

Data and statistical analyses

196 Variables were averaged for 5 minutes at pre-exercise baseline and for every 1 minute during 197 exercise. SR and CVC were plotted against the changes in $\mathrm{T}_{\mathrm{es}}\left(\Delta \mathrm{T}_{\mathrm{es}}\right)$ and $\mathrm{T}_{\mathrm{b}}\left(\Delta \mathrm{T}_{\mathrm{b}}\right)$ during 
198 exercise to assess the core temperature threshold and slope for inducing the responses.

199 Segmented regression analysis was used to determine the core temperature onset thresholds 200 and slopes of local SR and cutaneous vasodilation at each skin site (Cheuvront et al. 2009). The 201 slopes were defined based on the linear portion of the changes in SR and CVC before and after 202 the appearance of the onset thresholds during the exercise.

Baseline data in the BR and PL conditions were compared using a paired Student's t-test. $T_{\text {es }}$ and $\mathrm{T}_{\mathrm{b}}$ thresholds and slopes for SR and CVC between BR and PL were compared using two way-repeated measures ANOVAs (condition $\times$ skin region). HR, MAP, $\mathrm{T}_{\mathrm{es}}, \mathrm{T}_{\mathrm{sk}}$, and RPE during exercise were compared using two way-repeated measures ANOVAs (condition $\times$ time) with comparisons of baseline and each 5 minutes of exercise (baseline, 5, 10, 15, 20, 25, and 30 minutes). Three way-repeated measures ANOVAs were performed (condition $\times$ time $\times$ skin region) for SR and CVC during exercise. A Greenhouse-Geisser correction was applied if the assumption of sphericity was been violated. A Bonferroni correction was applied to control for the multiple comparisons. When an influence of BR supplementation was observed, a linear regression analysis was performed to determine the relationship between $\dot{V} \mathrm{O}_{2 \max }$ and the variables (see results). The effect size of each ANOVA was calculated and reported as partial eta-squared values $\left(\eta_{\mathrm{p}}{ }^{2}\right)$ and that of each t-test was calculated and reported as Cohen's $d(d)$. Data are presented as mean $\pm \mathrm{SD}$, and statistical significance was set at $P<0.05$. All statistical analyses were performed using a statistical package (SPSS) version 24.0.

RESULTS

220

Plasma nitrate and nitrite concentrations

222 Compared with PL, three days BR juice supplementation increased resting plasma $\mathrm{NO}_{3}{ }^{-}[P=$ 0.000, $\mathrm{d}=4.916,1-\beta=1.000,95 \%$ confidence interval for mean difference $\left(\mathrm{CI}_{95}\right)=390$ to 729 $\mu \mathrm{M}]$ and $\mathrm{NO}_{2}{ }^{-}\left(P=0.011, \mathrm{~d}=2.222,1-\beta=1.000, \mathrm{CI}_{95}=88\right.$ to $410 \mu \mathrm{M}$, Table 1$)$.

227 There were no differences in $\operatorname{HR}\left(P=0.262, \mathrm{~d}=0.190,1-\beta=0.110, \mathrm{CI}_{95}=-1\right.$ to 5 beats $\left./ \mathrm{min}\right)$ and $\operatorname{MAP}\left(P=0.173, \mathrm{~d}=0.416,1-\beta=0.344, \mathrm{CI}_{95}=-9\right.$ to $\left.2 \mathrm{mmHg}\right)$ at rest between $\mathrm{PL}$ and $\mathrm{BR}$ supplementations (Table 2). Resting $\mathrm{T}_{\mathrm{es}}\left(P=0.069, \mathrm{~d}=0.667,1-\beta=0.704, \mathrm{CI}_{95}=-0.01\right.$ to $\left.0.23^{\circ} \mathrm{C}\right), \mathrm{T}_{\mathrm{b}}\left(P=0.051, \mathrm{~d}=0.118,1-\beta=0.635, \mathrm{CI}_{95}=0\right.$ to $\left.0.20^{\circ} \mathrm{C}\right)$, and $\mathrm{T}_{\mathrm{sk}}(P=0.616, \mathrm{~d}=$ 
231

232

233

234

235

236

237

238

239

240

241

242

243

244

245

246

247

248

249

250

251

252

253

254

255

256

257

258

259

260

261

262

263

0.526, $1-\beta=0.504, \mathrm{CI}_{95}=-0.23$ to $0.36{ }^{\circ} \mathrm{C}$ ) were not different in BR compared with PL (Table 2). A supplementation $\times$ time interaction effect was observed for $\operatorname{MAP}\left(P=0.035, \eta_{\mathrm{p}}{ }^{2}=0.265\right.$, $1-\beta=0.782$, Fig. 1). Post hoc analysis revealed that the BR supplementation lowered MAP during exercise, which attained significance after 30 min of exercise (112 \pm 6 and $103 \pm 6$ mmHg for PL and BR, respectively, $P=0.021, \eta_{\mathrm{p}}{ }^{2}=0.559,1-\beta=0.724, \mathrm{CI}_{95}=-15$ to -2 $\mathrm{mmHg}$ ) but not $15 \min \left(110 \pm 2\right.$ and $105 \pm 4 \mathrm{mmHg}$, respectively, $P=0.093, \eta_{\mathrm{p}}{ }^{2}=0.350,1-\beta=$ 0.389, $\mathrm{CI}_{95}=-11$ to $1 \mathrm{mmHg}$ ) or $20 \mathrm{~min}(110 \pm 2$ and $105 \pm 4 \mathrm{mmHg}$, respectively, $P=0.060$, $\eta_{\mathrm{p}}{ }^{2}=0.418,1-\beta=0.489, \mathrm{CI}_{95}=-11$ to $0 \mathrm{mmHg}$ ) of exercise (Fig. 1 ). The attenuation of MAP in BR relative to PL at 30 min of exercise was related to the levels of $\dot{V} \mathrm{O}_{2 \text { max }}$ such that individuals with smaller $\dot{V}_{2 \max }$ showed a larger attenuation of $\operatorname{MAP}\left(P=0.048, \mathrm{R}^{2}=0.50\right)$. Neither a main effect of supplementation (all $P \geq 0.129$, all $\eta_{\mathrm{p}}{ }^{2} \leq 0.298$, all $1-\beta \leq 0.319$ ) nor an interaction (all $P \geq 0.069$, all $\eta_{\mathrm{p}}{ }^{2} \leq 0.312$, all $1-\beta \leq 0.529$ ) was observed for $\mathrm{HR}, \mathrm{T}_{\mathrm{es}}, \mathrm{T}_{\mathrm{sk}}, \mathrm{T}_{\mathrm{b}}$, and RPE during exercise (Fig. 1).

\section{Sweating and cutaneous vascular responses}

Neither a main effect of supplementation $\left(P=0.164, \eta_{\mathrm{p}}{ }^{2}=0.256,1-\beta=0.270\right)$ nor an interaction effect (all $P \geq 0.121$, all $\eta_{\mathrm{p}}{ }^{2} \leq 0.250$, all $1-\beta \leq 0.437$ ) was observed in SR during exercise (Fig. 2). Similarly, there were no main effects of supplementation (all $P \geq 0.114$, all $\eta_{\mathrm{p}}{ }^{2}$ $\leq 0.318$, all $1-\beta \leq 0.346$ ) and skin region (all $P \geq 0.089$, all $\eta_{\mathrm{p}}{ }^{2} \leq 0.358$, all $1-\beta \leq 0.401$ ) or these interaction effect (all $P \geq 0.135$, all $\eta_{\mathrm{p}}{ }^{2} \leq 0.289$, all $1-\beta \leq 0.309$ ) for $\mathrm{T}_{\mathrm{es}}$ and $\mathrm{T}_{\mathrm{b}}$ thresholds and slopes for SR (Table 3). A higher SkBF and CVC on the chest compared to the forearm was observed as indicated by a significant main effect of skin region during exercise (SkBF; $P=$ $0.008, \eta_{\mathrm{p}}{ }^{2}=0.660,1-\beta=0.883, \mathrm{CI}_{95}=0.116$ to $0.530 \mathrm{AU}, \mathrm{CVC} ; P=0.012, \eta_{\mathrm{p}}{ }^{2}=0.619,1-\beta=$ 0.823, $\mathrm{CI}_{95}=0.001$ to $0.012 \mathrm{AU} / \mathrm{mmHg}$, Fig. 2). The BR supplementation and regional difference did not affect $\mathrm{T}_{\text {es }}$ and $\mathrm{T}_{\mathrm{b}}$ thresholds and slopes for CVC such that there were no main effects of supplementation (all $P \geq 0.087$, all $\eta_{\mathrm{p}}{ }^{2} \leq 0.360$, all $1-\beta \leq 0.403$ ) and skin region (all $P$ $\geq 0.079$, all $\eta_{\mathrm{p}}{ }^{2} \leq 0.377$, all $1-\beta \leq 0.427$ ) or these interaction effect (all $P \geq 0.305$, all $\eta_{\mathrm{p}}{ }^{2} \leq$ 0.149 , all $1-\beta \leq 0.161$ ) for $\mathrm{T}_{\mathrm{es}}$ and $\mathrm{T}_{\mathrm{b}}$ thresholds and slopes for CVC (Table 3).

\section{DISCUSSSION}

Contrary to our hypothesis, BR supplementation did not affect local SR and cutaneous vascular responses on the chest or forearm during exercise in hot conditions. On the other hand, we observed a lowered end-exercise blood pressure following BR supplementation during 
264

265

266

267

268

269

270

271

272

273

274

275

276

277

278

279

280

281

282

283

284

285

286

287

288

289

290

291

292

293

294

295

296

exercise in hot conditions. These results suggest that $\mathrm{NO}_{3}{ }^{-}$-rich $\mathrm{BR}$ juice supplementation is not likely to influence local sweating and cutaneous vascular responses, but can lower systemic blood pressure during exercise in a hot environment.

Previous studies have reported a fundamental role for NO in the regulation of sweating during exercise, as evidenced by a reduction in SR when NOS activity was inhibited at the skin (Welch et al. 2009; Fujii et al. 2016; Fujii et al. 2015). In the present study, plasma $\mathrm{NO}_{3}{ }^{-}$and $\mathrm{NO}_{2}{ }^{-}$were significantly increased by BR supplementation (Table 1), implying an increased potential for $\mathrm{O}_{2}$-independent NO production (Lundberg et al. 2008). We reasoned that BR supplementation would increase $\mathrm{NO}_{2}{ }^{-}$delivery to sweat glands where cutaneous blood flow was higher, thereby promoting an enhanced sweat response mediated by NO (Welch et al. 2009; Fujii et al. 2016; Fujii et al. 2015). We further assumed that $\mathrm{NO}_{3}{ }^{-}$and $\mathrm{NO}_{2}{ }^{-}$in sweat secreted onto the skin would be reduced to NO, and hence may have diffused through the skin to increase SkBF (Vercelino et al. 2013). However, the BR-induced increase in plasma $\mathrm{NO}_{3}{ }^{-}$and $\mathrm{NO}_{2}{ }^{-}$did not affect local SR on either the forearm or chest (Fig. 2). In addition, slopes describing the relationship between sweating response on the chest and forearm against the increase in core temperature were not affected by BR supplementation (Table 3). Therefore, contrary to the previously reported influence of NOS-dependent NO production on sweat regulation (Welch et al. 2009; Fujii et al. 2016; Fujii et al. 2015), it appears that augmenting the $\mathrm{NO}_{3}{ }^{-} \rightarrow \mathrm{NO}_{2}{ }^{-} \rightarrow \mathrm{NO}$ pathway does not modify the sweat response during exercise in the heat, at least following short-term BR administration (3 days) employed herein. Given that $\mathrm{NO}_{2}{ }^{-}$-derived $\mathrm{NO}$ production is potentiated within hypoxic and acidic tissues (Lundberg et al. 2008), there remains the possibility that exogenous $\mathrm{NO}_{3}{ }^{-}$-supplementation may modulate sweating in hot environments at simulated altitude or during high- intensity exercise when NOS-dependent sweating is abolished (Fujii et al. 2014) as well as in exercising older individuals (Stapleton et al. 2014). In addition, given that NOS-dependent sweating is highly variable between individuals (Amano et al. 2017a; Amano et al. 2017b), it is conceivable that enhancing the $\mathrm{NO}_{3}{ }^{-} \rightarrow \mathrm{NO}_{2}{ }^{-} \rightarrow \mathrm{NO}$ pathway may benefit some (but not all) individuals via an improved sweating response when exercising in the heat. Therefore, further studies are required to elucidate the precise influence of inorganic $\mathrm{NO}_{3}^{-}$treatment on sweating during exercise.

It has recently been reported that $\mathrm{NO}_{3}{ }^{-}$supplementation increased CVC during passive heating (Levitt et al. 2015). These authors also reported that the increased CVC was due to a reduction 
297 in MAP during normothermic resting and passive hyperthermic conditions, whilst the SkBF 298 per se was not influenced by the supplementation (Levitt et al. 2015). We did not observe 299 measurable differences in CVC between conditions (Fig. 2) despite a reduction in MAP during 300 exercise (Fig. 1). Given that the CVC was not measurably impacted by BR supplementation in 301 the present study (Fig. 2), despite a reduction in mean arterial pressure during exercise (Fig. 1), 302 it appears that BR supplementation has a distinct influence on cutaneous vascular response 303 between whole body passive heating and exercise. However, the mechanisms for the disparate 304 effects of BR supplementation on cutaneous blood flow during exercise and rest in 305 hyperthermic conditions are unknown and therefore warrants further research.

306

307 Numerous studies have reported a reduction in blood pressure at rest (Bailey et al. 2009; Keen et al. 2014; Levitt et al. 2015; Larsen et al. 2006; Sobko et al. 2010; Wylie et al. 2013a; Lee et al. 2015) and during exercise (Lee et al. 2015; Bond $\mathrm{Jr}$ et al. 2013) following $\mathrm{NO}_{3}{ }^{-}$ supplementation. Whilst we did not observe a reduction in blood pressure at rest with $\mathrm{NO}_{3}{ }^{-}$ treatment (Table 2), this lack of effect has also been reported in some previous studies following $\mathrm{NO}_{3}{ }^{-}$supplementation (Cermak et al. 2012; Larsen et al. 2010; Gilchrist et al. 2013).

313 In contrast to previous studies that reported an influence of $\mathrm{NO}_{3}{ }^{-}$supplementation on blood 314 pressure within thermoneutral ambient conditions, it is noteworthy that we reported a lowering of blood pressure with BR during exercise in a hot environment. On the other hand, a very recent study reported that BR supplementation does not alter blood pressure during exercise in trained cyclists $\left(\dot{V}_{2 \max }, 68 \mathrm{ml} / \mathrm{kg} / \mathrm{min}\right)$ in hot conditions (Kent et al. 2018). Given that our participants were comparatively less trained $\left(\dot{V} \mathrm{O}_{2 \max }, 43 \mathrm{ml} / \mathrm{kg} / \mathrm{min}\right)$ to those assessed in the study by Kent et al. (2018), it is possible that aerobic fitness accounted for the inter-study disparity in blood pressure following BR supplementation during exercise in hot conditions. To support this observation, we found that individuals with lower aerobic fitness manifest a larger attenuation of blood pressure during exercise in a hot environment. Notwithstanding this novel observation, given that unstable and falling blood pressure can signal cardiovascular failure during exercise in the heat (Rowell 1974), our data suggest that ingesting $\mathrm{NO}_{3}{ }^{-}$-rich $\mathrm{BR}$ prior to exercising in the heat should be implemented with caution, particularly since its effect on exercise performance in a hot environment is currently controversial (Kent et al. 2017; McQuillan et al. 2017). While the potential ergogenic effects of BR supplementation appear to be inversely related to aerobic fitness (Porcelli et al. 2015) and is recommended to enhance endurance performance in recreationally-active individuals in thermoneutral conditions (Jones 2014), BR supplement should be used with caution in hot environments to limit the potential 
331 for the development of excessive hypotension. It is also interesting that we observed the

332

333

334

335

336

337

338

339

340

341

342

343

344

345

346

347

348

349

350

351

352

353

354 In summary, we showed that three days of BR juice supplementation, which increased plasma 355

356

357

358

359

360

361 reduction of MAP at the end of exercise only. It is expected that the lowering blood pressure at the end of exercise might be associated with the fall of blood $\mathrm{pH}$ and $\mathrm{PO}_{2}$ that potentiate the reduction of $\mathrm{NO}_{2}{ }^{-}$to $\mathrm{NO}$ (Castello et al. 2006; Modin et al. 2001) while future investigation is needed to confirm this possibility. Clearly, further studies are required to elucidate the impact and safety of the blood pressure lowering effects of BR supplementation during exercise in hot conditions.

\section{Limitations}

There were several limitations in the present study. Firstly, while we observed increases in plasma $\mathrm{NO}_{3}{ }^{-}$and $\mathrm{NO}_{2}{ }^{-}$concentrations, it was unclear whether $\mathrm{NO}_{3}{ }^{-}$and $\mathrm{NO}_{2}{ }^{-}$delivery to sweat glands, and by extension the potential for NO synthesis, was increased in the present study. Future research should assess sweat $\mathrm{NO}_{3}{ }^{-}$and $\mathrm{NO}_{2}{ }^{-}$concentrations to verify or refute this possibility. Secondly, given that we did not normalize CVC as \% of maximum vasodilation as has previously been conducted (Keen et al. 2014; Levitt et al. 2015), the potential inter-day and inter-site variations in cutaneous vascular response might have influenced the reliability of CVC in the present study. Finally, while we tried to conduct female experiments in the same phase of menstrual cycle, there remained a possibility that the circulating sex hormone levels differed between the trials since we did not measure blood sex hormones concentrations in the present study. Given that the sex hormone levels might affect local cutaneous blood flow response through NO dependent mechanism (Charkoudian et al. 1999), this point is worthy of future study.

$\mathrm{NO}_{3}{ }^{-}$and $\mathrm{NO}_{2}{ }^{-}$, had no influence on sweating and cutaneous vascular responses at multiple skin sites during exercise in a hot condition among healthy young adults. However, BR juice supplementation lowered mean arterial blood pressure whilst exercising in the heat. Further research is required to assess the risk-reward weighting of this hypotensive effect during exercise in a hot environment. 


\section{REFERENCES}

Amano T, Fujii N, Kenny GP, Inoue Y, Kondo N (2017a) Do nitric oxide synthase and cyclooxygenase contribute to sweating response during passive heating in endurance-trained athletes? Physiological Reports 5 (15):e13403

Amano T, Fujii N, Louie JC, Meade RD, Kenny GP (2017b) Individual variations in nitric oxide synthase dependent sweating in young and older males during exercise in the heat: role of aerobic power. Physiol Report 5:e13208

Bailey SJ, Winyard P, Vanhatalo A, Blackwell JR, DiMenna FJ, Wilkerson DP, Tarr J, Benjamin N, Jones AM (2009) Dietary nitrate supplementation reduces the O2 cost of low-intensity exercise and enhances tolerance to high-intensity exercise in humans. J Appl Physiol 107 (4):1144-1155

Bateman RM, Ellis CG, Freeman DJ (2002) Optimization of nitric oxide chemiluminescence operating conditions for measurement of plasma nitrite and nitrate. Clin Chem 48 (3):570-573

Benjamin N, O’Driscoll F, Dougall H, Duncan C, Smith L, Golden M (1994) Stomach NO synthesis. Nature 368:502

Bond Jr V, Curry BH, Adams RG, Millis RM, Haddad GE (2013) Cardiorespiratory function associated with dietary nitrate supplementation. Applied Physiology, Nutrition, and Metabolism 39 (2):168-172

Borg G (1970) Perceived exertion as an indicator of somatic stress. Scand J Rehabil Med 2 (2):92-98

Breese BC, Poole DC, Okushima D, Bailey SJ, Jones AM, Kondo N, Amano T, Koga S (2017) The effect of dietary nitrate supplementation on the spatial heterogeneity of quadriceps deoxygenation during heavy - intensity cycling. Physiological reports 5 (14):e13340

Burry J, Coulson H, Esser I, Marti V, Melling S, Rawlings A, Roberts G, Mills A (2001) Erroneous gender differences in axillary skin surface/sweat $\mathrm{pH}$. International journal of cosmetic science 23 (2):99-107

Castello PR, David PS, McClure T, Crook Z, Poyton RO (2006) Mitochondrial cytochrome oxidase produces nitric oxide under hypoxic conditions: implications for oxygen sensing and hypoxic signaling in eukaryotes. Cell metabolism 3 (4):277-287

Cermak NM, Gibala MJ, van Loon LJ (2012) Nitrate supplementation's improvement of 10-km time-trial performance in trained cyclists. International Journal of Sport Nutrition andExercise Metabolism 22 (1):64

Charkoudian N, Stephens DP, Pirkle KC, Kosiba WA, Johnson JM (1999) Influence of female reproductive hormones on local thermal control of skin blood flow. J Appl Physiol 87 (5):1719-1723

Cheuvront SN, Bearden SE, Kenefick RW, Ely BR, Degroot DW, Sawka MN, Montain SJ (2009) A simple and valid method to determine thermoregulatory sweating threshold and sensitivity. J Appl Physiol 107 (1):69-75

Duncan C, Dougall H, Johnston P, Green S, Brogan R, Leifert C, Smith L, Golden M, Benjamin N (1995) Chemical generation of nitric oxide in the mouth from the enterosalivary circulation of dietary nitrate. Nat Med 1 (6):546-551

Fujii N, McGinn R, Stapleton JM, Paull G, Meade RD, Kenny GP (2014) Evidence for cyclooxygenase-dependent sweating in young males during intermittent exercise in the heat. J Physiol 592 (Pt 23):5327-5339. doi:10.1113/jphysiol.2014.280651

Fujii N, Meade RD, Alexander LM, Akbari P, Foudil-Bey I, Louie JC, Boulay P, Kenny GP (2016) iNOS-dependent sweating and eNOS-dependent cutaneous vasodilation are evident in younger adults, but are diminished in older adults exercising in the heat. $\mathrm{J}$ Appl Physiol 120:318-327. doi:10.1152/japplphysiol.00714.2015 
411

412

413

414

415

416

417

418

419

420

421

422

423

424

425

426

427

428

429

430

431

432

433

434

435

436

437

438

439

440

441

442

443

444

445

446

447

448

449

450

451

452

453

454

455

456

457

458

459

460
Fujii N, Paull G, Meade RD, McGinn R, Stapleton JM, Akbari P, Kenny GP (2015) Do nitric oxide synthase and cyclooxygenase contribute to the heat loss responses in older males exercising in the heat? J Physiol 593:3169-3180. doi:10.1113/jp270330

Gilchrist M, Winyard PG, Aizawa K, Anning C, Shore A, Benjamin N (2013) Effect of dietary nitrate on blood pressure, endothelial function, and insulin sensitivity in type 2 diabetes. Free Radic Biol Med 60:89-97

Govoni M, Jansson EÅ, Weitzberg E, Lundberg JO (2008) The increase in plasma nitrite after a dietary nitrate load is markedly attenuated by an antibacterial mouthwash. Nitric Oxide 19 (4):333-337

Havenith G, Fogarty A, Bartlett R, Smith CJ, Ventenat V (2008) Male and female upper body sweat distribution during running measured with technical absorbents. Eur J Appl Physiol 104 (2):245-255. doi:10.1007/s00421-007-0636-z

Hertzman AB, Randall WC (1948) Regional differences in the basal and maximal rates of blood flow in the skin. J Appl Physiol 1 (3):234-241

Jones AM (2014) Dietary nitrate supplementation and exercise performance. Sports Med 44 Suppl 1:S35-45. doi:10.1007/s40279-014-0149-y

Kapil V, Milsom AB, Okorie M, Maleki-Toyserkani S, Akram F, Rehman F, Arghandawi S, Pearl V, Benjamin N, Loukogeorgakis S (2010) Inorganic nitrate supplementation lowers blood pressure in humans. Hypertension 56 (2):274-281

Keen JT, Levitt EL, Hodges GJ, Wong BJ (2014) Short-term dietary nitrate supplementation augments cutaneous vasodilatation and reduces mean arterial pressure in healthy humans. Microvasc Res 98C:48-53. doi:10.1016/j.mvr.2014.12.002

Kellogg DL, Crandall CG, Liu Y, Charkoudian N, Johnson JM (1998) Nitric oxide and cutaneous active vasodilation during heat stress in humans. J Appl Physiol 85 (3):824-829

Kent GL, Dawson B, Cox GR, Abbiss CR, Smith KJ, Croft KD, X. LZ, Eastwood A, Burke LM, Peeling P (2018) Effect of dietary nitrate supplementation on thermoregulatory and cardiovascular responses to submaximal cycling in the heat. European Journal of Applied Physiology 118 (3):657-668

Kent GL, Dawson B, Cox GR, Burke LM, Eastwood A, Croft KD, Peeling P (2017) Dietary nitrate supplementation does not improve cycling time-trial performance in the heat. $\mathrm{J}$ Sports Sci:1-8

Kerger H, Torres Filho I, Rivas M, Winslow R, Intaglietta M (1995) Systemic and subcutaneous microvascular oxygen tension in conscious Syrian golden hamsters. American Journal of Physiology-Heart and Circulatory Physiology 268 (2):H802-H810

Kuennen M, Jansen L, Gillum T, Granados J, Castillo W, Nabiyar A, Christmas K (2015) Dietary nitrate reduces the $\mathrm{O}$ cost of desert marching but elevates the rise in core temperature. Eur J Appl Physiol. doi:10.1007/s00421-015-3255-0

Kuno Y (1956) Human Perspiration. Charles C. Thomas, Springfield, Illinois.

Lansley KE, Winyard PG, Bailey SJ, Vanhatalo A, Wilkerson DP, Blackwell JR, Gilchrist M, Benjamin N, Jones AM (2011) Acute dietary nitrate supplementation improves cycling time trial performance. Med Sci Sports Exerc 43 (6):1125-1131

Larsen FJ, Ekblom B, Sahlin K, Lundberg JO, Weitzberg E (2006) Effects of dietary nitrate on blood pressure in healthy volunteers. N Engl J Med 355 (26):2792-2793

Larsen FJ, Weitzberg E, Lundberg JO, Ekblom B (2010) Dietary nitrate reduces maximal oxygen consumption while maintaining work performance in maximal exercise. Free Radic Biol Med 48 (2):342-347

Lee JS, Stebbins CL, Jung E, Nho H, Kim JK, Chang MJ, Choi HM (2015) Effects of chronic dietary nitrate supplementation on the hemodynamic response to dynamic exercise. Am J Physiol Regul Integr Comp Physiol 309 (5):R459-466. 
doi:10.1152/ajpregu.00099.2015

Levitt EL, Keen JT, Wong BJ (2015) Augmented reflex cutaneous vasodilatation following short-term dietary nitrate supplementation in humans. Exp Physiol. doi:10.1113/ep085061

Lundberg JO, Weitzberg E, Gladwin MT (2008) The nitrate-nitrite-nitric oxide pathway in physiology and therapeutics. Nature reviews Drug discovery 7 (2):156

McNamara TC, Keen JT, Simmons GH, Alexander LM, Wong BJ (2014) Endothelial nitric oxide synthase mediates the nitric oxide component of reflex cutaneous vasodilatation during dynamic exercise in humans. J Physiol. doi:10.1113/jphysiol.2014.272898

McQuillan JA, Casadio JR, Dulson DK, Laursen PB, Kilding AE (2017) The Effect of Nitrate Supplementation on Cycling Performance in the Heat in Well-Trained Cyclists. International Journal of Sports Physiology and Performance:1-22

Mitchell D, Wyndham CH (1969) Comparison of weighting formulas for calculating mean skin temperature. J Appl Physiol 26 (5):616-622

Modin A, Björne H, Herulf M, Alving K, Weitzberg E, Lundberg J (2001) Nitrite - derived nitric oxide: a possible mediator of 'acidic-metabolic' vasodilation. Acta Physiologica 171 (1):9-16

Moncada S, Higgs E (1991) Endogenous nitric oxide: physiology, pathology and clinical relevance. Eur J Clin Invest 21 (4):361-374

Morimoto T, Johnson RE (1967) Ammonia and the regulation of acidity in human eccrine sweat. Nature 216 (5117):813-814

Porcelli S, Ramaglia M, Bellistri G, Pavei G, Pugliese L, Montorsi M, Rasica L, Marzorati M (2015) Aerobic fitness affects the exercise performance responses to nitrate supplementation. Med Sci Sports Exerc 47 (8):1643-1651

Rowell LB (1974) Human cardiovascular adjustments to exercise and thermal stress. Physiol Rev 54 (1):75-159

Shastry S, Dietz NM, Halliwill JR, Reed AS, Joyner MJ (1998) Effects of nitric oxide synthase inhibition on cutaneous vasodilation during body heating in humans. J Appl Physiol 85 (3):830-834

Smith CJ, Havenith G (2011) Body mapping of sweating patterns in male athletes in mild exercise-induced hyperthermia. Eur J Appl Physiol 111 (7):1391-1404. doi:10.1007/s00421-010-1744-8

Sobko T, Marcus C, Govoni M, Kamiya S (2010) Dietary nitrate in Japanese traditional foods lowers diastolic blood pressure in healthy volunteers. Nitric Oxide 22 (2):136-140

Spiegelhalder B, Eisenbrand G, Preussmann R (1976) Influence of dietary nitrate on nitrite content of human saliva: possible relevance to in vivo formation of $\mathrm{N}$-nitroso compounds. Food Cosmet Toxicol 14 (6):545-548

Stapleton JM, Fujii N, Carter M, Kenny GP (2014) Diminished nitric oxide-dependent sweating in older males during intermittent exercise in the heat. Exp Physiol 99:921-932. doi:10.1113/expphysiol.2013.077644

Stolwijk JA, Hardy JD (1966) Partitional calorimetric studies of responses of man to thermal transients. J Appl Physiol 21 (3):967-977

Taylor NA, Machado-Moreira CA (2013) Regional variations in transepidermal water loss, eccrine sweat gland density, sweat secretion rates and electrolyte composition in resting and exercising humans. Extrem Physiol Med 2 (1):4. doi:10.1186/2046-7648-2-4

Vercelino R, Cunha TM, Ferreira ES, Cunha FQ, Ferreira SH, de Oliveira MG (2013) Skin vasodilation and analgesic effect of a topical nitric oxide-releasing hydrogel. Journal of Materials Science: Materials in Medicine 24 (9):2157-2169

Welch G, Foote KM, Hansen C, Mack GW (2009) Nonselective NOS inhibition blunts the sweat response to exercise in a warm environment. J Appl Physiol 106 (3):796-803 
511

512

513

514

515

516

517

518

519

520

521

522

523

524

525

526
Weller R, Pattullo S, Smith L, Golden M, Ormerod A, Benjamin N (1996) Nitric oxide is generated on the skin surface by reduction of sweat nitrate. J Invest Dermatol 107 (3):327-331

Wilkins BW, Holowatz LA, Wong BJ, Minson CT (2003) Nitric oxide is not permissive for cutaneous active vasodilatation in humans. The Journal of physiology 548 (3):963-969

Wylie LJ, Kelly J, Bailey SJ, Blackwell JR, Skiba PF, Winyard PG, Jeukendrup AE, Vanhatalo A, Jones AM (2013a) Beetroot juice and exercise: pharmacodynamic and dose-response relationships. J Appl Physiol (1985) 115 (3):325-336. doi:10.1152/japplphysiol.00372.2013

Wylie LJ, Kelly J, Bailey SJ, Blackwell JR, Skiba PF, Winyard PG, Jeukendrup AE, Vanhatalo A, Jones AM (2013b) Beetroot juice and exercise: pharmacodynamic and dose-response relationships. J Appl Physiol 115 (3):325-336.

doi:10.1152/japplphysiol.00372.2013 


\section{ACKNOWLEDGMENTS}

528 We thank our volunteer subjects for participating in this study.

529

\section{CONFLICTS OF INTEREST}

531 None.

532

\section{GRANTS}

534 This study was partly supported by a Grant-in-Aid for Scientific Research (no. 15K14618, 535 17H02153, and 26882026) from the Japan Society for the Promotion of Science from the 536 Ministry of Education, Culture, Sports, Science, and Technology of Japan. 
538 FIGURE LEGENDS

539

540 Figure 1. Heart rate (HR), mean arterial blood pressure (MAP), oesophageal temperature ( $\mathrm{T}_{\mathrm{es}}$ ),

541 mean skin temperature $\left(\mathrm{T}_{\mathrm{sk}}\right)$, mean body temperature $\left(\mathrm{T}_{\mathrm{b}}\right)$, and ratings of perceived exertion

542 (RPE) during exercise in PL and BR conditions. \# indicates a significant difference between

543 conditions at a given time point $(P=0.021)$.

544

545 Figure 2. Sweat rate (SR), skin blood flow (SkBF), and cutaneous vascular conductance

546 (CVC) on forearm and chest during exercise in PL and BR conditions.

547

548

549 
550 Table 1. Plasma nitrate and nitrite concentrations.

\begin{tabular}{lll}
\hline \hline & \multicolumn{1}{c}{$\mathrm{PL}$} & $\mathrm{BR}$ \\
\hline $\mathrm{NO}_{3}{ }^{-}(\mu \mathrm{M})$ & $21(6)$ & $581(161) *$ \\
$\mathrm{NO}_{2}^{-}(\mathrm{nM})$ & $87(28)$ & $336(156) *$ \\
\hline \hline
\end{tabular}

551 The values given are the means (SD). $\mathrm{NO}_{3}{ }^{-}$, nitrate; $\mathrm{NO}_{2}{ }^{-}$, nitrite. ${ }^{*}$ Significantly higher than

552 that of PL $(P \leq 0.011)$.

553

554 
555 Table 2. Physiological variables at rest.

\begin{tabular}{lll}
\hline & \multicolumn{1}{c}{ PL } & BR \\
\hline HR (beats/min) & $63(11)$ & $65(10)$ \\
$\mathrm{MAP}(\mathrm{mmHg})$ & $89(8)$ & $85(11)$ \\
$\mathrm{T}_{\mathrm{es}}\left({ }^{\circ} \mathrm{C}\right)$ & $36.87(0.12)$ & $36.98(0.20)$ \\
$\mathrm{T}_{\mathrm{sk}}\left({ }^{\circ} \mathrm{C}\right)$ & $34.42(0.58)$ & $34.48(0.42)$ \\
$\mathrm{T}_{\mathrm{b}}\left({ }^{\circ} \mathrm{C}\right)$ & $36.38(0.18)$ & $36.48(0.20)$ \\
\hline \hline
\end{tabular}

556

557 The values given are the means (SD). HR, heart rate; MAP, mean arterial blood pressure; $\mathrm{T}_{\mathrm{es}}$,

558 oesophageal temperature; $T_{\text {sk }}$, mean skin temperature; $T_{b}$, mean body temperature.

559

560 
561 Table 3. Oesophageal and mean body temperatures thresholds and slopes for sweating and 562 cutaneous vasodilation during exercise.

\begin{tabular}{|c|c|c|c|c|c|}
\hline & & \multicolumn{2}{|c|}{$\begin{array}{c}\text { SR } \\
\end{array}$} & \multicolumn{2}{|c|}{ CVC } \\
\hline & & PL & $\mathrm{BR}$ & PL & $\mathrm{BR}$ \\
\hline \multicolumn{6}{|c|}{ Forearm } \\
\hline \multirow[t]{4}{*}{$\mathrm{T}_{\mathrm{es}}$} & Threshold $\left({ }^{\circ} \mathrm{C}\right)$ & $36.98(0.21)$ & $37.07(0.24)$ & $37.06(0.16)$ & $37.16(0.25)$ \\
\hline & $\Delta$ Threshold $\left({ }^{\circ} \mathrm{C}\right)$ & $0.11(0.16)$ & $0.09(0.12)$ & $0.19(0.18)$ & $0.18(0.16)$ \\
\hline & $\begin{array}{l}\text { slopes } \\
\left(\mathrm{mg} / \mathrm{cm}^{2} / \mathrm{min} /{ }^{\circ} \mathrm{C}\right)\end{array}$ & $1.27(0.46)$ & $1.43(0.45)$ & - & - \\
\hline & $\begin{array}{l}\text { slopes } \\
\left(\mathrm{AU} / \mathrm{mmHg} /{ }^{\circ} \mathrm{C}\right)\end{array}$ & - & - & $\begin{array}{l}0.0150 \\
(0.0052)\end{array}$ & $\begin{array}{l}0.0215 \\
(0.0117)\end{array}$ \\
\hline \multirow[t]{4}{*}{$\mathrm{T}_{\mathrm{b}}$} & Threshold $\left({ }^{\circ} \mathrm{C}\right)$ & $36.41(0.21)$ & $36.50(0.22)$ & $36.49(0.14)$ & $36.56(0.21)$ \\
\hline & $\Delta$ Threshold $\left({ }^{\circ} \mathrm{C}\right)$ & $0.03(0.09)$ & $0.01(0.04)$ & $0.11(0.16)$ & $0.08(0.08)$ \\
\hline & $\begin{array}{l}\text { slopes } \\
\left(\mathrm{mg} / \mathrm{cm}^{2} / \mathrm{min} /{ }^{\circ} \mathrm{C}\right)\end{array}$ & $1.73(0.70)$ & $1.92(0.76)$ & - & - \\
\hline & $\begin{array}{l}\text { slopes } \\
\left(\mathrm{AU} / \mathrm{mmHg} /{ }^{\circ} \mathrm{C}\right)\end{array}$ & - & - & $\begin{array}{l}0.0222 \\
(0.0082)\end{array}$ & $\begin{array}{l}0.0260 \\
(0.0142)\end{array}$ \\
\hline
\end{tabular}

Chest

\begin{tabular}{|c|c|c|c|c|c|}
\hline \multirow[t]{4}{*}{$\mathrm{T}_{\mathrm{es}}$} & Threshold $\left({ }^{\circ} \mathrm{C}\right)$ & $37.01(0.21)$ & $37.10(0.27)$ & $37.04(0.15)$ & $37.15(0.24)$ \\
\hline & $\Delta$ Threshold $\left({ }^{\circ} \mathrm{C}\right)$ & $0.14(0.15)$ & $0.12(0.14)$ & $0.17(0.13)$ & $0.17(0.10)$ \\
\hline & $\begin{array}{l}\text { slopes } \\
\left(\mathrm{mg} / \mathrm{cm}^{2} / \mathrm{min} /{ }^{\circ} \mathrm{C}\right)\end{array}$ & $1.58(0.61)$ & 2.09 (1.33) & - & - \\
\hline & $\begin{array}{l}\text { slopes } \\
\left(\mathrm{AU} / \mathrm{mmHg} /{ }^{\circ} \mathrm{C}\right)\end{array}$ & - & - & $\begin{array}{l}0.0180 \\
(0.0062)\end{array}$ & $\begin{array}{l}0.0247 \\
(0.0146)\end{array}$ \\
\hline \multirow[t]{4}{*}{$\mathrm{T}_{\mathrm{b}}$} & Threshold $\left({ }^{\circ} \mathrm{C}\right)$ & $36.42(0.21)$ & $36.52(0.23)$ & $36.44(0.20)$ & $36.56(0.21)$ \\
\hline & $\Delta$ Threshold $\left({ }^{\circ} \mathrm{C}\right)$ & $0.04(0.09)$ & $0.04(0.06)$ & $0.06(0.08)$ & $0.09(0.07)$ \\
\hline & $\begin{array}{l}\text { slopes } \\
\left(\mathrm{mg} / \mathrm{cm}^{2} / \mathrm{min} /{ }^{\circ} \mathrm{C}\right)\end{array}$ & 2.15 (1.13) & $2.42(1.04)$ & - & - \\
\hline & $\begin{array}{l}\text { slopes } \\
\left(\mathrm{AU} / \mathrm{mmHg} /{ }^{\circ} \mathrm{C}\right)\end{array}$ & - & - & $\begin{array}{l}0.0273 \\
(0.0082)\end{array}$ & $\begin{array}{l}0.0288 \\
(0.0144)\end{array}$ \\
\hline
\end{tabular}

563 The values given are the means (SD). $\mathrm{T}_{\mathrm{es}}$, oesophageal temperature; $\mathrm{T}_{\mathrm{b}}$, mean body temperature;

564 SR, sweat rate; CVC, cutaneous vascular conductance. 

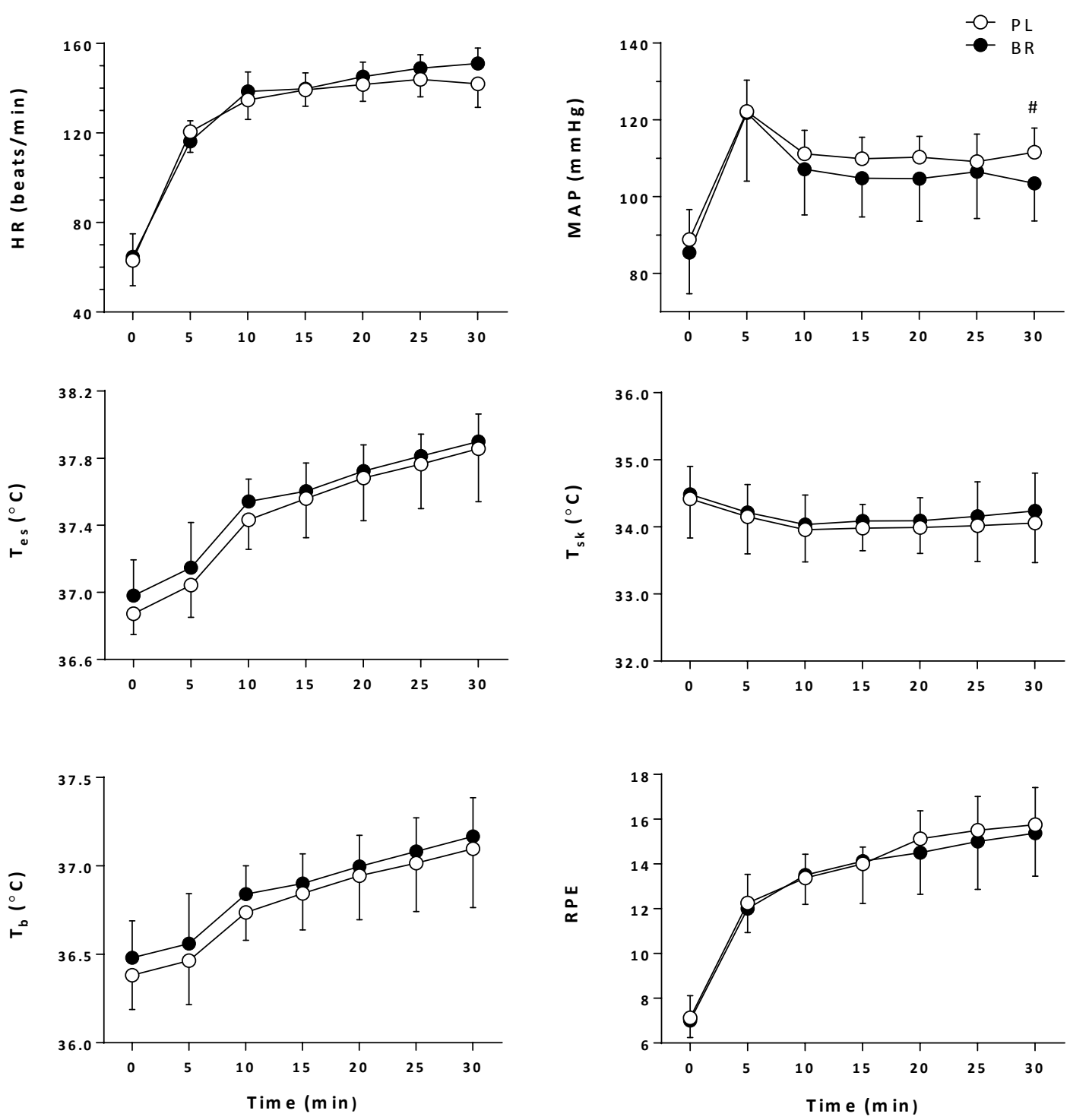

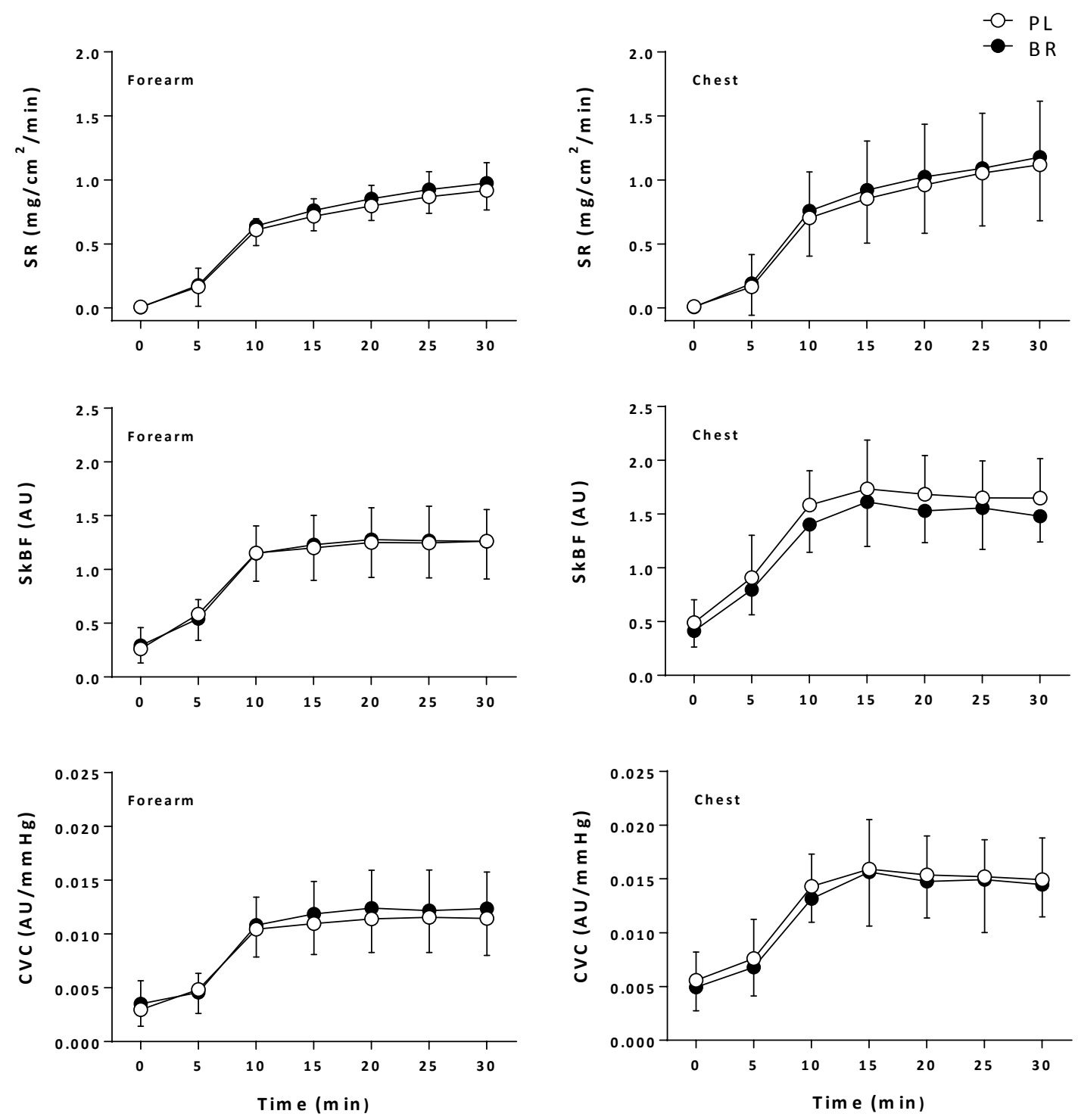

571

572

Fig. 2 